
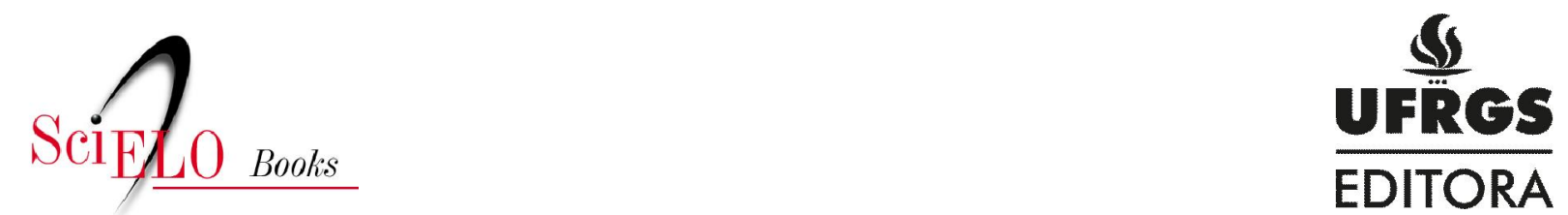

\title{
Padrões históricos da mudança tecnológica e ondas longas do desenvolvimento capitalista
}

\author{
César S. Conceição \\ Luiz A. E. Faria
}

SciELO Books / SciELO Livros / SciELO Libros

CONCEIÇÃO, CS., and FARIA, LA. Padrões históricos da mudança tecnológica e ondas longas do desenvolvimento capitalista. In: DATHEIN, R., org. Desenvolvimentismo: o conceito, as bases teóricas e as políticas [online]. Porto Alegre: Editora da UFRGS, 2003. Estudos e pesquisas IEPE series, pp. 223-255. ISBN 978-85-386-0382-5. Available from doi: 10.7476/9788538603825. Also available in ePUB from: http://books.scielo.org/id/8m95t/epub/dathein-9788538603825.epub.

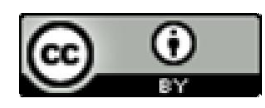

All the contents of this work, except where otherwise noted, is licensed under a Creative Commons Attribution 4.0 International license.

Todo o conteúdo deste trabalho, exceto quando houver ressalva, é publicado sob a licença Creative Commons Atribição $\underline{4.0}$.

Todo el contenido de esta obra, excepto donde se indique lo contrario, está bajo licencia de la licencia $\underline{\text { Creative Commons }}$ Reconocimento 4.0. 


\section{Padrões históricos da mudança tecnológica e ondas longas do desenvolvimento capitalista}

César S. Conceição

Luiz A. E. Faria

I should premise that I use the term Struggle for Existence in a large and Metaphorical Sense, including dependence of one being on another, and including success in leaving progeny.

Charles Darwin

The changes in the economic process brought about by innovation, together with all their effects, and the response to them by the economic system, we shall designate by the term Economic Evolution.

Joseph A. Schumpeter

\section{Introdução}

O presente capítulo tem como objetivo fazer uma discussão do processo de desenvolvimento econômico na perspectiva evolucionária. Tal perspectiva busca mostrar que o desenvolvimento é caracterizado pela coevolução das tecnologias e instituições (Nelson, 2011). No entanto, esse processo de evolução não ocorre de maneira contínua ao longo do tempo, mas sim através de sucessivas ondas de mudança estrutural provocadas pela emergência e difusão de revoluções tecnológicas (Freeman; Louçã, 2001). Na base desse processo estão as inovações e suas interações com sistemas tecnológicos, cujo progressivo desenvolvimento caracteriza o padrão de crescimento do período, concentrado em setores e indústrias específicas.

Nessa concepção, desde a Revolução Industrial até a Revolução da Informação no século XXI, o sistema econômico capitalista atravessou cinco ondas de "destruição criadora", resultante da emergência e propagação das revoluções tecnológicas (Perez, 2002). As inovações são 
o elemento central da transformação estrutural das economias capitalistas, e estão na base do surgimento de firmas, indústrias, setores, produtos e serviços inteiramente novos, capazes de caracterizar o padrão de crescimento de um período ou as sucessivas fases históricas do desenvolvimento capitalista.

A partir das observações históricas, as revoluções tecnológicas surgem nos países industrializados e se difundem tardiamente para os países mais atrasados. Na interpretação evolucionária, cada sucessiva revolução tecnológica conduz a uma massiva substituição do conjunto de tecnologias existentes por tecnologias superiores, bem como à revitalização de setores industriais (Freeman; Louçã, 2001; Perez, 2010). Essas mudanças profundas levam à transformação do modo de organização da sociedade, nos tipos de habilidades requeridas pelas indústrias. Da mesma forma, implicam recorrente necessidade de ajuste do marco institucional e regulatório capaz de ampliar e facilitar o funcionamento das novas tecnologias - ou da "nova economia" (Perez, 2010). Ao revolucionar as estruturas produtivas e conduzir ao surgimento de sucessivos padrões de produção e de organização da atividade produtiva nas firmas, cada revolução tecnológica implica um processo de divergência das taxas de crescimento e, portanto, de desequilíbrio entre diferentes firmas, indústrias, países e regiões mundiais. $\mathrm{O}$ restabelecimento das condições e a plena utilização do novo potencial trazido pelas novas tecnologias são um processo complexo e que dependem, portanto, das condições sociais e econômicas, historicamente alcançadas pelos países ao longo do tempo.

As diferentes trajetórias e padrões de crescimento de longo prazo observados na economia mundial são o resultado desse processo cíclico e evolutivo de mudança tecnológica e estrutural, na qual o papel das instituições é essencial para dar suporte à geração, à difusão e à exploração do conhecimento tecnológico, bem como à implementação das mudanças organizacionais e estratégias das firmas. Nessa perspectiva, as nações que se mostram mais favoráveis às mudanças institucionais adequadas aos novos "paradigmas tecnoeconômicos" exibem rápido crescimento e ingressam em uma trajetória de catching up e desenvolvimento. Em outra perspectiva, a rigidez ou inércia institucional dos países pode resultar na prolongada incompatibilidade entre seu sistema institucional e o crescimento potencial das novas tecnologias, inviabilizando o ingresso em uma trajetória de desenvolvimento com catching 
up. Nesse sentido, a compreensão do processo de desenvolvimento na tradição evolucionária permite explicar as diferentes trajetórias seguidas pelos países ao longo do tempo.

Para tanto, o capítulo está organizado da seguinte forma. Na primeira seção, busca-se fazer uma discussão teórica do papel da mudança tecnológica na compreensão da dinâmica e evolução do sistema econômico, com destaque para as contribuições de Marx e Schumpeter. $\mathrm{Na}$ segunda seção, busca-se compreender a forma como ocorre o processo de evolução e mudança econômica através da emergência e difusão das inovações e revoluções tecnológicas. Na terceira seção são analisadas as implicações da emergência e difusão das revoluções tecnológicas na explicação das sucessivas ondas de desenvolvimento capitalista, ressaltando aspectos históricos e irregulares da difusão entre os países. A quarta seção discute as implicações da irregularidade da propagação das revoluções tecnológicas entre os países para explicar o processo desigual de desenvolvimento e, dessa forma, as distintas trajetórias de catching up e falling behind que caracterizam os padrões históricos do desenvolvimento capitalista.

\section{Inovação, mudança estrutural e evolução econômica}

Desde Adam Smith, Ricardo, Marx e, posteriormente, Schumpeter e Keynes, até os modelos neoclássicos de crescimento, existe uma unanimidade no pensamento econômico de que o processo de crescimento da produtividade de longo prazo das economias está intimamente relacionado à introdução e à difusão das inovações técnicas e organizacionais. No entanto, apenas Marx, no século XIX, e Schumpeter, no século $\mathrm{XX}$, deram à inovação papel central em suas teorias do crescimento econômico (Freeman, 2008).

O dinamismo tecnológico, impulsionado pela concorrência capitalista e pelo conflito capital-trabalho, se associa à emergência histórica das instituições capitalistas que favorecem e aceleram a mudança tecnológica e, com isso, o próprio processo de acumulação de capital. Sob uma perspectiva histórica: "[...] o desenvolvimento das forças produtivas constitui a lei de movimento da economia capitalista, onde o capital deve revolucionar as condições técnicas e organizacionais do processo de traba- 
lho, de modo a aumentar a produtividade do trabalho" (Marx, 1982, p. 510). Nesse contexto, o principal modo das firmas capitalistas manterem a competitividade é mediante o aumento da produtividade com a introdução de máquinas novas e mais eficientes. Para Marx, a concorrência capitalista atua como um mecanismo de permanente introdução de progresso técnico, capaz de tornar endógeno ao sistema capitalista o processo de mudança estrutural via inovações (Possas, 2002, p. 417).

Diferentemente dos estágios anteriores das sociedades, quando o objetivo da comunidade e dos indivíduos era a reprodução das condições de produção determinadas, no capitalismo, “[...] o capital põe a própria produção de riqueza como pressuposto de sua reprodução e, consequentemente, o desenvolvimento universal de suas forças produtivas, a contínua revolução de seus pressupostos existentes" (Marx, 2011, p. 447). Nesse contexto, Marx (2011, p. 446) afirma que o desenvolvimento da ciência - isto é, a forma mais sólida da riqueza - é um aspecto importante para o desenvolvimento das forças produtivas humanas, e, assim, da própria riqueza. O desenvolvimento da ciência (ou da base científica), juntamente com a aplicação das leis da mecânica e da química, permite à máquina realizar atividades que eram desenvolvidas anteriormente pelo próprio trabalhador. Com isso, Marx afirma que

[...] o desenvolvimento da maquinaria por essa via só ocorre quando a grande indústria já atingiu um estágio mais elevado e o conjunto das ciências já se encontra cativo a serviço do capital. Por outro lado, a própria maquinaria existente já proporciona elevados recursos. A invenção torna-se então um negócio e a aplicação da ciência à própria produção imediata, um critério que a determina e solicita (Marx, 2011, p. 587).

À medida que a grande indústria se desenvolve, a criação da riqueza efetiva passa a depender menos do tempo de trabalho e da quantidade empregada do que do poder dos agentes postos em movimento. Conforme observado por Marx, a criação da riqueza passa a depender cada vez mais "do nível geral da ciência e do progresso da tecnologia, ou da aplicação dessa ciência à produção" (Marx, 2011, p. 588). O avanço tecnológico é considerado essencial para o progresso econômico e um elemento crítico na luta concorrencial das empresas e das nações (Freeman; Soete, 2008, p. 18). 
Nesse contexto, Marx enfatiza a natureza descontínua da evolução social, um processo evolucionário que ocorre de maneira progressiva no capitalismo. Ao longo do tempo histórico, novas forças produtivas emergem, não exogenamente ou como um misterioso "Deus ex machina", mas como resultado de um processo dialético e histórico amplo, no qual as forças produtivas mais antigas e as relações de produção desempenham papel fundamental (Rosenberg, 2006, p. 75). Nesse sentido, a visão de Marx das inter-relações históricas entre a ciência e tecnologia deve ser tratada como um ponto de partida para as inter-relações imensamente mais complexas que caracterizam o desenvolvimento capitalista.

Sobretudo, três pontos essenciais da teoria Marxista podem ser destacados, conforme observou Schumpeter (1964, p. 74): as manifestações culturais da sociedade são fundamentalmente funções de sua estrutura de classes (o que não implica uma determinação causal); a estrutura de classes de uma sociedade é governada pela estrutura de produção; e por fim, o processo social da produção apresenta uma evolução imanente, isto é, uma tendência a variar seus dados econômicos e, portanto, também os sociais. Para Schumpeter (1964, p. 75) essa é uma visão evolucionária. Conforme o autor:

[...] a análise marxista é a única teoria genuinamente evolucionista que o período produziu [...] A grande visão de uma evolução imanente do processo econômico - de como operando através da acumulação, certa forma destrói a economia bem como a sociedade e o capitalismo competitivo, e, outra forma, produz uma situação social insustentável [...] dando luz a uma outra organização social (Schumpeter, 1964, p. 75).

Inspirado em Marx, Schumpeter trouxe questões que, mais tarde, entrariam no centro do debate do processo de desenvolvimento econômico: o papel da mudança tecnológica (inovações) no processo de evolução e mudança do sistema econômico. Schumpeter, no entanto, não aceita muitas das características da teoria de Marx. Para ele, os lucros são definidos exclusivamente pelo surgimento do empresário, e não pela exploração política e social da classe capitalista.

Na sua teoria, a firma e o empresário são os veículos da inovação, responsáveis pela transformação do sistema, sendo a competição o elemen- 
to propulsor das inovações que causam o processo de evolução e as mudanças estruturais do sistema econômico. A concorrência com inovações tem caráter dinâmico, pois estabelece a vantagem decisiva de custo ou qualidade que atinge, não a fímbria dos lucros e das produções das firmas existentes, mas suas fundações e suas próprias vidas (Schumpeter, 1961).

A habilidade e a iniciativa do empresário, apoiado nas descobertas de cientistas e inventores, criam oportunidades inteiramente novas para o investimento, crescimento e emprego. Os lucros dessas inovações são o impulso decisivo para as novas ondas de crescimento, atuando como mecanismos de atração para imitadores. À medida que esse processo ocorre, a lucratividade vai sendo disputada até a recessão se configurar, e todo o processo pode seguir para uma depressão, até que inicie o rápido crescimento da nova onda de mudança tecnológica, organizacional e social.

Freeman (2008, p. 75) destaca que, enquanto a teoria do crescimento na perspectiva Keynesiana dá ênfase à administração da demanda, a teoria neoclássica enfatiza a correção das imperfeições de mercado e a flexibilidade de preços, a perspectiva de Schumpeter enfatiza o investimento autônomo incorporado de inovações tecnológicas como a base do desenvolvimento econômico. Nessa estrutura, o crescimento econômico deve ser visto como um processo de realocação de recursos entre as indústrias e firmas. Esse processo necessariamente conduz a mudanças estruturais e desequilíbrios porque as taxas de mudança tecnológica são diferentes entre as diversas indústrias. $\mathrm{O}$ crescimento econômico não é meramente acompanhado pelo crescimento e expansão das novas indústrias, mas depende principalmente de sua expansão (Freeman, 2008, p. 75).

A análise de Schumpeter, portanto, é voltada a compreender os efeitos da mudança tecnológica sobre as transformações estruturais das economias, cujas novas estruturas emergem em um sistema sujeito a rupturas e a descontinuidades. O capitalismo é entendido como um processo evolucionário de contínua introdução de inovações e como um processo de destruição criadora, tal como havia enfatizado Marx (Freeman; Louçã, 2001). Nessa perspectiva, o aspecto essencial que se deve captar do sistema capitalista é seu caráter evolutivo, uma forma ou método de mudança econômica que nunca pode estar estacionário (Schumpeter, 1961, p. 112).

A questão teórica central de Schumpeter é a análise das causas do movimento do sistema econômico, em especial, seus movimentos cí- 
clicos e de evolução. Nesse sentido, sua teoria buscou compreender os fatores que influenciam e alteram o sistema de maneira endógena, o que permite analisar suas características inerentes (Schumpeter, 1989, p. 2). Em Business cycles, Schumpeter (1989, p. 61) define precisamente sua visão evolucionária da mudança econômica, ao afirmar que o processo de evolução econômica decorre das "mudanças do processo econômico trazido pelas inovações, juntamente com todos seus efeitos e respostas dadas pelo sistema econômico". A história é repleta de violentas mudanças e catástrofes, as quais constituem a forma como o sistema capitalista evolui. A evolução ocorre com “[...] distúrbios das estruturas existentes, mais como uma série de explosões do que uma suave, embora incessante, transformação" (Schumpeter, 1989, p. 77). Nesse sentido, o conceito de evolução é equivalente à noção de desenvolvimento econômico, e a economia é entendida, teoricamente, como um processo evolucionário, sempre mudando no tempo histórico.

Contudo, apesar da inovação estar no centro da discussão teórica do processo de crescimento econômico e de desenvolvimento, a análise de Schumpeter não tem como foco a origem das inovações ou a gestão das inovações em nível microeconômico. Como observado por Freeman (2011, p. 130), os ciclos econômicos de Schumpeter são uma consequência direta do aparecimento do cluster das inovações, no entanto, não se explica por que as inovações surgem de forma agrupada ou formando clusters ou com tipos particulares de periodicidade.

O que encoraja e induz a inovação e, portanto, explica por que elas se agrupam no tempo e em determinados setores, para Schumpeter, é a existência de indivíduos "supernormais", dotados de inteligência e energia excepcional (Freeman, 2011, p. 132). Tal perspectiva, segundo o autor, sugere uma relativa negação de alguns elementos que são essenciais para uma teoria satisfatória dos ciclos econômicos: a interdependência tecnológica e econômica de muitas inovações e a existência de trajetórias tecnológicas (Freeman, 2011, p. 132). Da mesma forma, sua análise minimiza também as inovações incrementais, as quais são menos produto dos empresários, mas sim efeito cumulativo influenciado pelo ambiente institucional, que é diferenciado entre os países.

A história da ciência, tecnologia, invenção, inovação e difusão das inovações mostra o papel importante das grandes descobertas e inovações na transformação do sistema econômico, como destacado por 
Schumpeter. No entanto, é importante o reconhecimento das inumeráveis contribuições que são menores em termos de impacto e que são incrementais, juntamente com as instituições que permitem acumular, disseminar e aplicar do novo conhecimento no sistema econômico. Nesse contexto, a invenção, inovação e a acumulação tecnológica devem ser consideradas resultado do processo social. Portanto, avançar na compreensão teórica do desenvolvimento econômico como um processo evolucionário requer reconhecer a importância das pequenas e grandes firmas, como também das instituições sociais (como laboratórios de pesquisa, departamentos de design, universidades, etc.), que, ao facilitarem as atividades de invenção e inovação das firmas, coevoluem com o avanço da tecnologia.

Nesse sentido, Perez (1983) e Freeman (2011) destacam a necessidade em avançar na teoria a partir de Schumpeter, ao reconhecer que a função do empresário pode ser desempenhada de maneira variada entre as diferentes firmas, tecnologias, países e períodos históricos. A compreensão desse processo dá origem ao conceito de sistemas nacionais de inovação ao incorporar a dimensão institucional do processo de inovação, compreendido pela rede de suporte de instituições técnicas e científicas, infraestrutura e o próprio ambiente social, cultural e econômico. Tal perspectiva vincula a contribuição de Schumpeter sobre o papel das inovações nos ciclos econômicos com a contribuição institucionalista, consolidando um amplo campo de pesquisa da moderna análise evolucionária (Nelson, 2011, p. 269).

A compreensão do avanço tecnológico e suas influências sobre o sistema econômico dá origem a uma forma particular de teoria de desenvolvimento, apresentada por Perez (1983) e Freeman e Perez (1988), capaz de explicar a diversidade de trajetórias de desenvolvimento dos países no tempo histórico.

\section{Mudança tecnológica, revoluções tecnológicas e desenvolvimento econômico}

Diante da importância da mudança tecnológica no processo de desenvolvimento econômico, a abordagem evolucionária busca analisar o processo de mudança tecnológica sobre a transformação das estruturas 
industriais e, dessa forma, sobre o sistema econômico. Dosi (2006, p. 25) propõe avaliar os fatores tecnológicos e os impulsos microeconômicos subjacentes ao crescimento e às transformações das economias modernas, com isso, analisar como as tendências tecnológicas se manifestam sobre as variáveis estruturais do sistema. Do ponto de vista dinâmico, sua análise revela a existência de assimetria entre firmas, em relação à fronteira da tecnologia, que vai mudando ao longo do tempo em resposta aos efeitos da mudança técnica das firmas, das novas formas de inovação, imitação e de interação competitivas entre empresas.

Para observar essas mudanças no sistema econômico, Dosi (2006, p. 25) destaca a necessidade de descrever os procedimentos e direção da mudança tecnológica, propondo analisar a mudança tecnológica e suas relações com o ambiente institucional, padrões de comportamento, estruturas de conhecimento, etc. $\mathrm{Na}$ visão neoclássica, a mudança tecnológica oscila entre a noção endógena (black box) e disponível para utilização - segundo a qual o dinheiro pagará o rumo de qualquer direção tecnológica e o ritmo que se desejar - a inovação puxada pela demanda (demand pull), e uma visão totalmente exógena, segundo a qual os agentes econômicos estão presos às pesquisas e avanços da ciência e engenharias (technological push).

Como forma de compreender a evolução da tecnologia, Dosi (1982) propõe o conceito de paradigmas tecnológicos como uma transposição do paradigma científico de Thomas Kuhn (2003) para o âmbito tecnológico. A mudança tecnológica é entendida como resultado de um processo evolucionário, que avança como resultado de uma variedade de esforços que contribuem para esse avanço. No curso de evolução da tecnologia, os esforços de inovação dos agentes (e invenção) dentro do processo competitivo não são estritamente cegos ou aleatórios. Parte do conhecimento que conduz ao avanço tecnológico reside na busca por solução de problemas específicos, baseados nas experiências operacionais práticas com as tecnologias, bem como nos avanços da ciência e das engenharias. O avanço tecnológico, portanto, “[...] não implica correspondência entre previsões e resultados, mas sim, envolve um longo processo de aprendizado, tentativas e erros, bem como resulta em um processo de seleção ex-post" (Dosi; Nelson, 2009, p. 8, tradução nossa).

A resolução de problemas tecnológicos nas firmas se dá por prescrições habituais que levam à focalização dos esforços em um conjunto 
de soluções possíveis. Ou seja, os comportamentos organizacionais das firmas seguem um conjunto de práticas normais, rotinas e procedimentos padronizados que, do ponto de vista do paradigma, não haveria melhores (ou possíveis). Nesse sentido, o autor propõe que as mudanças exógenas se relacionam à emergência desses novos padrões (ou paradigmas), enquanto as mudanças endógenas referem-se ao progresso técnico ao longo das trajetórias definidas por esse padrão estabelecido.

Apesar da existência dessa diversidade de agentes no processo de aprendizado e de experiências, se observa a existência de um padrão da mudança tecnológica que é relativamente invariante, bem como "[...] estruturas do conhecimento e formas em que o conhecimento tecnológico é acumulado" (Dosi; Nelson, 2009, p. 14). É justamente essa invariância do conhecimento que permite distinguir os diferentes campos e os diferentes períodos históricos do avanço tecnológico - identificados por Schumpeter -, e que explica os diferentes padrões de crescimento dos países, indústrias e firmas ao longo do tempo. Como observado por Dosi (1982):

\footnotetext{
[...] a história da tecnologia se associa à história da evolução das estruturas industriais. A emergência d'e novos paradigmas frequentemente se relaciona a novas companhias schumpeterianas, enquanto o seu estabelecimento apresenta um processo de estabilização oligopolista. (Dosi ,1982, p. 147).
}

A compreensão da forma como a tecnologia evolui, portanto, permite compreender como a tecnologia e a economia se influenciam mutuamente através do processo de inovação e concorrência. Tal perspectiva tem profundas implicações na compreensão do aprendizado, no âmbito microeconômico, da dinâmica industrial e do processo de crescimento econômico.

\subsection{Padrões de evolução da tecnologia e das revoluções tecnológicas}

A partir do conceito de paradigma tecnológico de Dosi (1982), os trabalhos de Perez (1983) e Freeman e Perez (1988) introduzem o conceito de paradigma tecnoeconômico como forma de descrever o conjunto de instituições que são necessárias para o emprego, exploração e desenvol- 
vimento efetivo das novas tecnologias. Dentro dessa perspectiva, Perez (1985, p. 442) enfatiza que a tecnologia é muito mais do que uma questão de ciência ou de engenharia: tecnologia é uma questão econômica e social (Perez, 1985, p. 442). O argumento dos autores é de que as tecnologias dominantes de uma época são fundamentais na formação do paradigma. O foco do conceito recai sobre a maneira de fazer as coisas, nos hábitos de pensar, nas formas institucionais e organizacionais, e não apenas na tecnologia no estrito sentido do termo (Nelson, 2011, p. 270).

Perez (1983) destaca que o processo de inovação se caracteriza pela aplicação e pela difusão das técnicas específicas na esfera produtiva, determinado pelas condições sociais e condições econômicas, objetivando o lucro. No entanto, esse processo de busca exige a tentativa permanente das firmas de transformar as invenções em inovações, ou seja, fazer com que as possibilidades tecnológicas e descobertas científicas se tornem realidades econômicas. Através das decisões de investimento e de financiamento, os esforços tecnológicos seguem direções particulares - ou paradigmas tecnológicos e suas trajetórias, na expressão de Dosi (1982). Nesse contexto, “[...] o espaço onde a mudança tecnológica necessita ser estudada é o da inovação, da convergência da tecnologia, da economia e do contexto socioinstitucional" (Perez, 2010, p. 186).

A partir da noção de paradigmas tecnológicos de Dosi (1982), as inovações seguem um padrão de evolução, de acordo com o qual a introdução de uma inovação radical torna-se objeto de inúmeras inovações incrementais que conduzem a sua otimização e padronização relativa do processo ou produto, até que seu avanço implique retornos decrescentes. Ou seja, as mudanças ocorrem lentamente no primeiro momento, enquanto produtores, projetistas e designers, distribuidores e consumidores se envolvem em um processo de feedback de aprendizagem (Perez, 2010, p. 187). Uma vez atingido um design dominante e estabelecido no mercado, quando alcança a fase de maturidade, o ritmo de inovações diminui. Ao longo do tempo, o nível de produtividade alcançado por um processo tecnológico particular avança sujeito a sucessivas melhorias através de investimento adicional, como ocorre em muitos processos de crescimento biológico e modelos epidêmicos.

Juntamente com o ritmo de desenvolvimento, uma trajetória também envolve a direção dentro do espaço de possibilidades. Como enfatizado, o paradigma representa a concordância dos agentes envolvi- 
dos, a padronização e o estabelecimento de hábitos de pensamentos na direção da pesquisa sobre aquilo que é considerado uma melhoria ou uma versão superior de produtos, serviços e tecnologia. ${ }^{1}$ Portanto, a noção de trajetória e paradigmas mostra a importância das inovações incrementais na trajetória seguida por cada inovação radical. Esse processo, que ocorre para as inovações individuais, em termos de regularidade do dinamismo e da direção da mudança técnica, "[...] também ocorre em nível mesoeconômico, na relação com a evolução de todos os produtos de uma indústria e em relação ao conjunto de indústrias inter-relacionadas" (Perez, 2010, p. 187). Essas noções e observações representam padrões que caracterizam a dinâmica da mudança tecnológica sobre a evolução industrial.

A mudança tecnológica, portanto, não ocorre em ritmo regular, nem de maneira aleatória. A análise do padrão de propagação das novas tecnologias através da economia tende a confirmar a visão de Schumpeter de que as inovações e sua difusão surgem agrupadas em "ondas", tendo importantes implicações para a explicação dos ciclos longos de crescimento econômico. Freeman e Soete (1997) destacam que as inovações individuais não surgem aleatoriamente, mas sim de maneira inter-relacionada com outras tecnologias. Essa inter-relação "dinâmica" entre as tecnologias constitui a formação de "sistemas tecnológicos" - ou constelações de inovações, na expressão de Freeman e Louçã (2001) - como forma de descrever a formação dos clusters e seu padrão de evolução subsequente. Como observa Freeman (1987):

Os novos sistemas ou paradigmas tecnológicos podem oferecer grandes vantagens tecnológicas e econômicas na ampla variedade de indústrias e serviços, cuja adoção se torna uma necessidade para qualquer economia exposta à pressão da competição econômica, social, política e militar. A ampla difusão mundial de tais paradigmas tecnoeconômi-

\footnotetext{
${ }^{1}$ Neste sentido, o paradigma é uma lógica coletiva convergente do potencial tecnológico, dos custos relativos, da aceitação de mercado, da coerência funcional e outros fatores. Os microprocessadores e produtos derivados são esperados para se tornarem mais rápidos, menores, mais potentes, mais versáteis, e relativamente mais baratos. Em contraste, automóveis, e aviões nos anos 1950 e 1960 eram supostos para se tornarem maiores, enquanto a velocidade, versatilidade não estavam entre os objetivos (Perez, 2010, p. 188).
} 
cos domina o processo de mudança tecnológica por muitas décadas e influência o desenvolvimento econômico e social, mesmo que não os determine de maneira única. $\mathrm{O}$ impulso para desenvolver tais novos paradigmas surge da persistente pressão competitiva para sustentar a lucratividade e produtividade e pela percepção dos limites para o crescimento em um paradigma estabelecido. (Freeman,1987, p. 61).

Esses padrões de mudança estrutural na economia, através das profundas consequências sociais, estão associados às ondas longas ou ciclos de Kondratiev e, portanto, relacionadas ao desenvolvimento de uma revolução tecnológica específica ${ }^{2}$.

Esse processo pode ser analisado pela evolução da tecnologia em nível mesoeconômico, no qual o processo de difusão também segue a forma logística e determina o padrão de crescimento do período. Conforme Figura 1, as inovações incrementais ao longo da trajetória, ao invés de melhorias incrementais, dão origem a sucessivos produtos, serviços e até mesmo novas indústrias, construída sobre o espaço criado pela inovação radical inicial e ampliada pelos seguidores, na tentativa de sua imitação. Os novos sistemas tecnológicos modificam o espaço comercial, assim como o contexto institucional e cultural. Assim, as novas regras e normas de regulação, treinamento especializado, normas e instituições (algumas vezes em substituição às já estabelecidas) são requeridas. No entanto, essas mudanças tendem a ter um forte efeito interativo de retroalimentação sobre as tecnologias, moldando e guiando a direção dentro das várias possibilidades existentes (Perez, 2010, p. 188).

\footnotetext{
${ }^{2} \mathrm{O}$ estudo de ciclos econômicos de longa duração teve início no final do século XIX, com trabalhos de Jevons (1884), Wicksell (1898), Parvus, e posteriormente, Van Gelderen (1913), Wolff (1924), entre outros. Porém, foi o trabalho de Kondratiev (1925) que constituiu a primeira tentativa sistemática para confirmar tais movimentos com dados que incluíram não somente séries de preços, juros e salários, mas também de comércio exterior, produção industrial e consumo para França, Grã-Bretanha e Estados Unidos (Freeman, 1984, p. 5). Kondratiev mostrou a existência de ciclos longos com duração média de 50 anos, observáveis a partir do século XVIII. A hipótese de Kondratiev deu origem a duas linhas de pesquisa histórica distinta, uma centrada na noção de ciclo de preços (ou de juros) e outra que se caracteriza como um fenômeno expresso em termos reais. Pelo lado real, a interpretação das flutuações e evolução de quantidades reais são consideradas efeito do processo de acumulação de capital, como destacado por Kondratiev, ou das inovações tecnológicas, como na tradição schumpeteriana.
} 


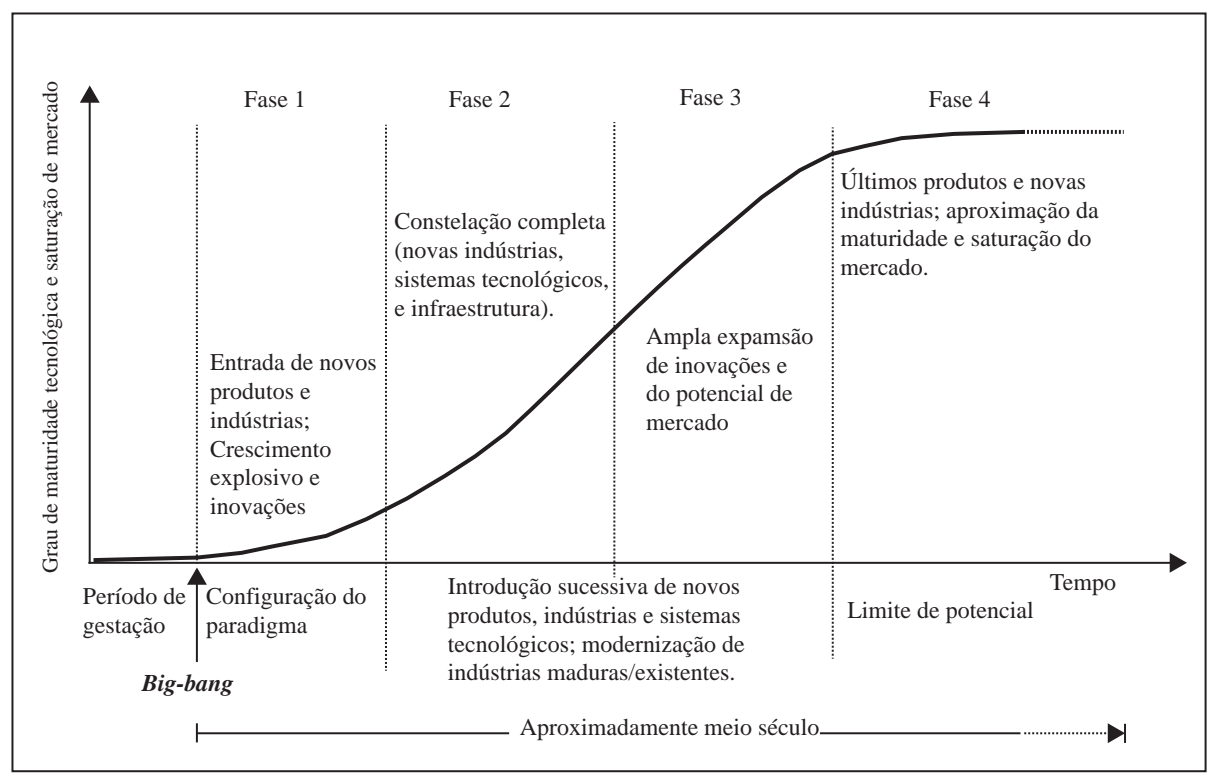

Figura 1. Ciclo de vida da revolução tecnológica

Fonte: PEREZ (2010).

Quando as possibilidades de inovação dos sistemas tecnológicos começam a reduzir e seus mercados correspondentes a apresentar sinais de saturação, a fase de maturidade é alcançada. Nas palavras de Perez, “[...] o ponto fundamental é que as tecnologias individuais não são introduzidas em isolado, mas sim em um contexto de mudança que influencia fortemente seu potencial, assim como as inovações do sistema anterior" (Perez, 2010, p. 188). Esse movimento cíclico ocorre porque os novos produtos que aparecem na fase inicial de um novo sistema tecnológico tendem a ter mercados mais dinâmicos em relação a aqueles introduzidos nas fases de maturidade ${ }^{3}$.

\footnotetext{
${ }^{3}$ Para Perez (2010), um dos motivos para essa tendência decorre do contexto de exaustão do espaço de oportunidades de um sistema particular. As inovações que surgem no final do ciclo tendem a ter impactos menores no sistema. Como exemplo, a autora cita as longas séries de eletrodomésticos introduzidas no início do século XX, iniciadas com o refrigerador, máquinas de lavar-roupa, etc., as quais foram se esgotando até chegar aos "abridores de lata e facas elétricas”. Isso ilustra o esgotamento das possibilidades de criação de novos produtos de um dado paradigma. Outro motivo se deve ao intenso aprendizado que ocorre
} 
Nesse sentido, Freeman e Perez (1988) sugerem uma taxonomia das inovações, fazendo a distinção entre inovação incremental e radical, novos sistemas tecnológicos, paradigmas tecnoeconômicos ou revoluções tecnológicas, como forma de elaborar as principais características da forma de evolução do sistema econômico e padrões de difusão através das ondas longas do desenvolvimento capitalista.

\subsection{Estrutura das revoluções tecnológicas e paradigmas tecnoeconômicos}

A partir da noção schumpeteriana de que a introdução das inovações pode dar origem a ondas e ciclos longos de crescimento, Perez (1985) busca mostrar que, ao trazer uma variedade aparente de tecnologias, cada onda longa (ou revolução tecnológica) traz um novo conjunto de princípios capazes de formar um senso comum que define uma ampla trajetória tecnológica em direção à fronteira geral das melhores práticas produtivas e organizacionais. Esses princípios são aplicados na “[...] geração de inovações e na organização da produção, firma a firma, ramo a ramo, dentro de cada país e entre países" (Perez, 1985, p. 443). À medida que ocorre o processo de propagação e evolução, ocorre um prolongado período de crescimento econômico, baseado na relativa elevação da taxa de lucro e dos ganhos de produtividade do sistema econômico. No entanto:

[...] gradualmente, como a variedade de aplicações é mais ou menos coberta de forma plena e, quando, através das sucessivas melhorias incrementais, a melhor fronteira efetivamente é aproximada, as forças subjacentes à onda de prosperidade diminuem. Como isso ocorre, o limite para o crescimento é encontrado por mais e mais setores da economia, e o crescimento da produtividade se reduz. (Perez, 1985, p. 443, tradução nossa).

dentro do sistema e pelas externalidades decorrentes, que tendem a acelerar a aceitação do usuário por um lado e, por outro, a reduzir o ciclo de vida do produto e seu tempo de rentabilidade. Como exemplo, Perez (2010, p. 188) afirma que demorou 24 anos, de 1954, para incorporar o ar-condicionado como uma forma de melhoria em $90 \%$ dos automóveis produzidos nos EUA, enquanto os pneus radiais, introduzidos em 1970, levaram menos de 8 anos para atingir o mesmo nível de penetração no mercado. 
Antes que a desaceleração do ritmo de crescimento se torne um fenômeno geral na economia, alguns setores e firmas mais dinâmicas começam a experimentar retornos decrescentes. Entre esses, passa a ocorrer um complexo processo de busca e de tentativa e erro estimulado pela busca de lucros. Esse processo "[...] resulta em ondas de fusão e de aquisição, várias formas de especulação, esforços para estender as tecnologias com a contenção de trabalho e com deslocamento" (Perez, 1985, p. 443, tradução nossa). No entanto, esse processo implica persistente pesquisa e busca por inovações lucrativas. Esse intenso feedback entre as esferas econômicas e tecnológicas pode conduzir, eventualmente, à emergência gradual e ao subsequente desenvolvimento de novos elementos tecnológicos. Nesses termos, a fase de declínio da onda longa de crescimento dá início a um processo de abandono do modelo esgotado e à propagação do novo.

Freeman e Perez (1988) e Perez (2002) destacam a ocorrência de cinco revoluções tecnológicas, inauguradas a partir de importantes descobertas e inovações tecnológicas, que deram origem a um universo novo de oportunidades para novos investimentos e inovações lucrativas, originando novas indústrias no sistema econômico. Ao distinguir uma revolução tecnológica de uma coleção aleatória de sistema tecnológico, Perez (2010, p. 189) destaca que uma revolução se baseia em duas características centrais e recorrentes no processo histórico: (i) forte interconectividade e interdependência entre sistemas, tecnologias e mercados; (ii) grande capacidade em transformar profundamente toda a economia (e eventualmente a sociedade $)^{4}$.

A primeira característica é a mais visível e define o que é popularmente entendido como revolução; mas, é a segunda que justifica a utilização do termo, por transformar outras indústrias e atividades através da difusão e influência do paradigma tecnoeconômico, definido como:

\footnotetext{
${ }^{4} \mathrm{~A}$ forte interconexão e interdependência das tecnologias ocorrem em vários níveis. Destacam-se os avanços do conhecimento científico e tecnológico pela utilização de princípios similares de engenharia, pela exigência de habilidades comuns no desenvolvimento e utilização das tecnologias - muitas vezes novas, pelo desenvolvimento de uma rede de fornecedores de insumos e serviços, assim como, de pontos de distribuição interdependentes e pelo dinamismo mutuamente determinado pelas várias interligações entre mercados; difusão de padrões coerentes de consumo e de utilização das novas tecnologias (Perez, 2010, p. 191).
} 
[...] modelo de melhores práticas para as maneiras mais efetivas de utilizar as novas tecnologias dentro e além das novas indústrias. Enquanto novos setores se expandem e se tornam o motor do crescimento por um longo período, o paradigma tecnoeconômico guia uma vasta reorganização e o aumento generalizado da produtividade entre as indústrias existentes. (Perez, 2010, p. 189).

A revolução tecnológica representa uma "grande mudança no potencial de criação da riqueza da economia" ao abrir um novo espaço para inovações e para novos conjuntos de tecnologias genéricas, infraestruturas e princípios organizacionais, que trazem ganhos de eficiência e efetividades em todas as atividades econômicas. A difusão de cada revolução tecnológica e do seu paradigma tecnoeconômico, portanto, juntamente com sua assimilação pela economia e pela sociedade, e dos ganhos resultantes de produtividade e expansão constituem as sucessivas grandes ondas de desenvolvimento capitalista observadas ao longo da história (Perez, 2010, p. 190).

Ao analisar a estrutura das revoluções tecnológicas e seus padrões de evolução, Perez (2010) observa o surgimento de novas seções na matriz de insumo-produto que, gradualmente, tornam-se as mais dinâmicas (e acabam por modificar o resto da economia). Em termos de estrutura, cada revolução tecnológica inclui um conjunto novo de produtos e tecnologias produtivas que são inter-relacionadas e dão origem a novas indústrias. Entre as novas indústrias, Perez (1983) mostra a importância de um insumo-chave - core - de uso geral, de custo decrescente e de ampla difusão na economia. Frequentemente, uma fonte de energia ou um material fundamental além do desenvolvimento de uma nova infraestrutura (que muitas vezes muda a fronteira e as condições das redes de transporte - de produtos, pessoas, energia e informação) (Perez, 2010, p. 191). O Quadro 1 ilustra as indústrias principais e infraestruturas características de cada revolução tecnológica, desde a Revolução Industrial na Inglaterra, no século XVIII. 
Quadro 1. Indústrias e infraestrutura de cada revolução tecnológica

\begin{tabular}{|c|c|c|}
\hline Revolução tecnológica & $\begin{array}{l}\text { Tecnologias e indústrias } \\
\text { novas ou redefinidas }\end{array}$ & Infraestrutura nova ou redefinida \\
\hline Revolução Industrial & $\begin{array}{l}\text { Mecanização da indústria têxtil } \\
\text { (algodão) /Ferro /Maquinário }\end{array}$ & $\begin{array}{l}\text { Canais e hidrovias/vias expressa com pe- } \\
\text { dágio/energia hidráulica (rodas hidráulicas } \\
\text { altamente melhoradas) }\end{array}$ \\
\hline Era do Vapor e ferrovias & $\begin{array}{l}\text { Motores e máquinas a vapor (feitos de ferro } \\
\text { e abastecidos pela extração de carvão) / } \\
\text { Ferro e carvão mineral (agora desempe- } \\
\text { nhando papel central para o crescimento) / } \\
\text { Construção das ferrovias/Energia a vapor } \\
\text { para muitas indústrias (incluindo têxtill) }\end{array}$ & $\begin{array}{c}\text { Ferrovias (com motor a vapor)/Serviços } \\
\text { postais; Telégrafos (principalmente ao longo } \\
\text { das linhas ferroviárias nacionais)/Grandes } \\
\text { portos }\end{array}$ \\
\hline Era do aço e engenharia pesada & $\begin{array}{l}\text { Aço/desenvolvimento de máquina a vapor em } \\
\text { navios de aço/Química pesada e engenharia } \\
\text { civil/indústria de equipamentos elétricos/ } \\
\text { cobre e cabos/papel e embalagens }\end{array}$ & $\begin{array}{l}\text { Transporte em todo o mundo em rápidos } \\
\text { navios de aço a vapor/Ferrovias transconti- } \\
\text { nentais/Grande pontes e túneis/Telégrafos } \\
\text { mundiais/telefones/rede elétrica de iluminação } \\
\text { e uso industrial }\end{array}$ \\
\hline $\begin{array}{c}\text { Era do petróleo, automóveis } \\
\text { e produção em massa }\end{array}$ & $\begin{array}{l}\text { Produção de automóveis em massa/petróleo } \\
\text { e combustíveis / Petroquímica (sintéticos) / } \\
\text { Motor a combustão interna para automóveis } \\
\text { e equipamentos de transporte, aviões, } \\
\text { tanques de guerra/ eletricidade/Eletrodomés- } \\
\text { ticos, refrigeradores, etc. }\end{array}$ & $\begin{array}{l}\text { Redes de estradas, rodovias, portos e } \\
\text { aeroportos/redes de dutos de petróleo/ } \\
\text { eletricidade universal (doméstica e indus- } \\
\text { trial) /Telecomunicações analógicas em todo } \\
\text { o mundo (telefone, telex e telegrama) com } \\
\text { e sem fio. }\end{array}$ \\
\hline $\begin{array}{l}\text { Era da informática } \\
\text { e telecomunicações }\end{array}$ & $\begin{array}{l}\text { Revolução da informação/chip microeletrôni- } \\
\text { co/ computadores, softwares/Telecomunica- } \\
\text { ções/ Instrumentos de controle/biotecnologia } \\
\text { e novos materiais auxiliados pelo computador }\end{array}$ & $\begin{array}{l}\text { Mundo digital das telecomunicações (cabo, } \\
\text { fibra ótica, rádio e satélite) /internet/e-mail/ } \\
\text { Transporte físico de alta velocidade (por } \\
\text { terra, água e ar) }\end{array}$ \\
\hline
\end{tabular}

Fonte: Elaborado a partir de Perez (2002).

Do ponto de vista da importância dos setores propulsores da mudança e da evolução, três tipos principais de setores (ramos) que determinam a forma e o ritmo do crescimento econômico de cada período ou revolução tecnológica podem ser identificados. Conforme Perez (1983), os setores podem ser distinguidos em (1) Ramos/setores "usuários" (Carrier branches), que demandam os insumos chave de maneira mais intensa e são mais adaptados à organização ideal da produção, induzem a grande variedade de oportunidades de investimentos, a jusante e a montante (entre os mais importantes, os grandes investimentos em tipos específicos de infraestrutura) e, dessa forma, se tornam vetores do estilo tecnológico, com influência no ritmo geral do crescimento. São indústrias que representam os produtos paradigmáticos da revolução, como computadores, softwares, telefones celulares na quinta revolução tecnológica, os automóveis e aparelhos elétricos na quarta, navios de aço movidos a vapor na terceira, locomotivas a vapor na segunda e máquinas têxteis na primeira; (2) Ramos motrizes (motive branches), responsáveis pela 
produção dos insumos-chave e outros insumos diretamente associados a estes e, portanto, têm o papel de manter e aprofundar sua vantagem relativa de custos. Enquanto o ramo motriz cria as condições para o desenvolvimento do estilo tecnológico, o crescimento e seus mercados dependem do ritmo de generalização do seu padrão entre as indústrias ${ }^{5}$; (3) O setor de infraestrutura, no qual ocorre parte da revolução em termos de tecnologia e seus impactos são sentidos na formação e extensão das fronteiras do mercado para todas as indústrias ${ }^{6}$.

Perez (1985) identifica também os efeitos das revoluções tecnológicas sobre os setores induzidos, os quais não são constituídos por indústrias revolucionárias, mas desenvolvem-se como consequência do crescimento e da complementaridade com ramos/setores/indústrias que utilizam as novas tecnologias (carrier branch). Portanto, uma vez realizadas as inovações sociais e institucionais, juntamente com o apropriado investimento em infraestrutura para essas tecnologias, é que se abre a possibilidade para a generalização/propagação do novo paradigma. Portanto, o surgimento de um conjunto de novas tecnologias merece o termo revolução, apenas se tiver capacidade de conduzir a uma ampla transformação em todas as indústrias. Além do uso das novas tecnologias, difundidas pela economia, modificam-se também as maneiras da organização das estruturas socioinstitucionais, através do surgimento do paradigma tecnoeconômico.

Portanto, além do novo conjunto tecnológico, uma revolução tecnológica também implica o estabelecimento de um novo paradigma tecnoeconômico, correspondente ao novo conjunto de práticas produtivas mais lucrativas e viáveis - em termos de escolhas de insumos, métodos e tecnologias -, juntamente com as novas estruturas organizacionais, modelos e estratégias empresariais (Perez, 2010, p. 194). Tais práticas se desenvolvem com a utilização das novas tecnologias, superando os obstáculos do mercado e encontrando procedimentos,

\footnotetext{
${ }^{5}$ Entre os exemplos, se destacam os "semicondutores na quinta revolução tecnológica, petróleo e plástico na quarta, aço na terceira, carvão na segunda e energia hidráulica na primeira (para os moinhos hidráulicos e transporte em canais)" (Perez, 2010, p. 191);

${ }^{6}$ Como a internet na quinta, estradas e eletricidade na quarta, a rede de transporte mundial (ferrovias transcontinentais, rotas de navios a vapor e portos) na terceira, ferrovias nacionais na segunda e canais na primeira.
} 
rotinas e estruturas mais adequadas, dando forma a princípios e critérios implícitos para a tomada de decisão das firmas.

As novas rotinas, heurísticas e métodos são internalizadas gradualmente nas firmas, tornando-se uma lógica "compartilhada" na economia ou senso comum novo e aceito na tomada de decisão de investimento das firmas, assim como no âmbito das escolhas e preferências dos consumidores. Nesse contexto, as ideias antigas tornam obsoletas, ignoradas, enquanto as novas tornam-se "normais". A mudança de paradigma representa uma ampla mudança nos hábitos e nas instituições como forma de viabilizar a utilização das novas tecnologias (Perez, 2010, p. 194).

A construção do novo paradigma tecnoeconômico ocorre simultaneamente em três áreas principais relacionadas às práticas e à percepção dos agentes: (I) dinâmica da estrutura de custos relativos dos insumos de produção (elementos novos de custos baixos e decrescentes se tornam atrativos para inovações lucrativas e do investimento); (II) no espaço percebido para inovações (onde as oportunidades das firmas são crescentemente mapeadas para o futuro desenvolvimento das novas tecnologias ou para a utilização vantajosa em setores existentes); (III) nos critérios e princípios organizacionais (as práticas exibem um desempenho melhor em determinados métodos e estruturas que objetivam tirar proveito do potencial das novas tecnologias para eficiência e máximos lucros) (Perez, 2010, p. 194).

Nas três áreas, a emergência do paradigma depende do ritmo da difusão dos produtos revolucionários, das tecnologias e da infraestrutura, juntamente com seus efeitos interativos que se autorreforçam. Nesse sentido, o primeiro impacto é localizado e mínimo, mas com o tempo, torna-se difundido e abrangente. Ou seja, passa a ocorrer, não apenas um processo de evolução tecnológica, com a adoção das novas tecnologias e mudanças ao longo das trajetórias, mas também um processo de mudança institucional na economia e no território, nos comportamentos e ideias, nos hábitos de pensamento, nas rotinas das firmas, etc. (Perez, 2010, p. 195).

Na visão de Perez (2010) e de Freeman e Louçã (2001), a adaptação mútua da tecnologia e da sociedade, através do aprendizado social do paradigma e do redesenho adaptativo da estrutura institucional, permite extrair o máximo benefício do potencial de geração de riqueza em cada "onda de desenvolvimento" (Perez, 2001). No entanto, quando o potencial do paradigma se esgota e a nova revolução começa a emergir, 
aqueles hábitos incorporados e as instituições agem como uma poderosa força inercial que precisa ser transformada para permitir a expansão da nova fase de desenvolvimento da revolução tecnológica seguinte. A compreensão da influência da mudança tecnológica de longo prazo é uma das mais importantes contribuições do pensamento evolucionário para a compreensão da macroeconomia formada pela dinâmica e pela história (Nelson, 2001). As observações revelam que os países que não fizerem as mudanças institucionais capazes de adequar aos novos paradigmas ficaram para trás no processo de desenvolvimento. Nessa perspectiva, as trajetórias de crescimento dos países e, portanto, do desenvolvimento, dependerão fundamentalmente dos seus esforços de aprendizado e de utilização das novas tecnologias.

\section{Revoluções tecnológicas e ondas longas de desenvolvimento}

Como observado por Schumpeter, as grandes mudanças tecnológicas não são dadas por uma série de infinitas melhorias marginais sobre as técnicas já estabelecidas, mas resultam da introdução de significativas descontinuidades geradas por inovações radicais ou, no caso da combinação de inovações, por revoluções tecnológicas. Essas profundas mudanças ocorridas nos últimos dois séculos caracterizam o padrão de evolução econômica que pode ser descrito como "sucessivas revoluções industriais". A adoção do termo "Revolução" se dá pelas evidências históricas de profundas mudanças na estrutura industrial, na tecnologia e no amplo sistema econômico. Essas mudanças se caracterizam por profundas descontinuidades e, por isso, merecem a designação de revoluções tecnológicas (Freeman; Louçã, 2001, p. 140).

Cada revolução tecnológica possui eventos notáveis e demonstram, não apenas viabilidade técnica dos principais produtos e processos novos, mas principalmente, um grande potencial de lucratividade no sistema econômico. Os novos produtos e técnicas industriais, inicialmente restritos a alguns setores, constituem novos modos de desenvolver, produzir, transportar e distribuir uma grande variedade de bens e serviços, permitindo assim, analisar as características históricas de cada período. É nesse sentido que surge a importância em analisar as rápidas e complexas mudanças nas tecnologias das sociedades indus- 
triais. A taxonomia ou classificação dos períodos permite compreender os sucessivos padrões de mudança na tecnologia, estrutura industrial e, dessa forma, do sistema econômico e social.

Freeman e Louçã (2001) observam que,

[...] a inovação e a difusão de novos produtos e novos processos não são eventos isolados, mas estão sempre e necessariamente relacionados com a disponibilidade de materiais, fornecimento de energia, componentes, habilidades (skills), infraestrutura, etc. Frequentemente, como Schumpeter observou, inovações aparecem em clusters e, raramente, são igualmente distribuídas no tempo ou no espaço (Freeman e Louçã 2001, p. 142, tradução nossa).

A compreensão da emergência das novas constelações tecnológicas e sua difusão até o período de esgotamento e turbulência são a base da explicação das ondas longas do desenvolvimento capitalista. No entanto, Freeman e Louçã (2001, p. 145) procuram mostrar a irregularidade do processo de difusão entre as economias. Para os autores, a taxa da difusão de produtos individuais é um processo que depende da maturidade de um sistema tecnológico. No caso dos novos produtos elétricos, o processo de difusão só pode ocorrer quando a infraestrutura estiver pronta, quando as competências e habilidades de eletricistas e engenheiros estiverem disponíveis, e quando as atitudes dos consumidores e o ambiente legislativo forem favoráveis às novas tecnologias. Nas fases iniciais de uma nova constelação tecnológica, estas barreiras podem causar atrasos no processo de difusão entre os países.

No ambiente de seleção das economias capitalistas, as inovações mais lucrativas provavelmente experimentam fases explosivas de crescimento, seguindo as suas primeiras aplicações bem-sucedidas. Como a tecnologia encontra uma crescente variedade de aplicações, os efeitos macroeconômicos podem ser substanciais. No entanto, o crescimento exponencial não pode continuar definitivamente. Como observado anteriormente, o estágio de maturidade é atingido quando a lucratividade é erodida e o crescimento se reduz. Novas tecnologias competem entre si, mas as tecnologias anteriormente dominantes não desaparecem, mas coexistem em um mundo de múltiplas tecnologias Freeman; Louçã, 2001, p. 146; Dosi; Nelson, 2009, p. 3). 
A partir da identificação simplificada das fases do ciclo de vida de um sistema tecnológico, é possível analisar como se estabelecem os padrões de crescimento. A partir de Perez (2002) e Freeman e Louçã (2001), seis fases de uma revolução tecnológica podem ser identificadas: uma primeira, caracterizada pelo período de invenção nos laboratórios, com os protótipos iniciais, patentes, demonstrações em pequena escala e em aplicações iniciais; a segunda, com a demonstração da viabilidade tecnológica e comercial do amplo potencial de aplicações; a terceira fase de "decolagem e crescimento explosivo", que ocorre com a turbulência, crise estrutural na economia, crise política de coordenação e com o estabelecimento de um ajuste institucional (ou regime de regulação); a quarta fase é de crescimento contínuo, dada pela aceitação do sistema e pela formação de um novo "senso comum", capaz de estabelecer o regime tecnológico de forma dominante nos países líderes da economia mundial e uma ampla aplicação na variedade de indústrias e serviços; a quinta fase marca a desaceleração e erosão da lucratividade, em virtude do amadurecimento do sistema tecnológico, que agora passa a ser desafiado pelo surgimento de novas tecnologias, levando a uma nova crise estrutural de ajustamento, e assim, sucessivamente. A sexta fase caracteriza a maturidade do sistema tecnológico, com alguns possíveis afeitos de renascimento pela coexistência com as novas tecnologias, mas também possibilidade de lento desaparecimento (Freeman; Louçã, 2001, p. 146).

O período entre a segunda e quinta fase do ciclo de vida da revolução tecnológica que está associado aos movimentos cíclicos do sistema econômico e social descrito como ondas longas ou ciclos longos de Kondratiev. Na sexta fase, o sistema tecnológico não tem maiores efeitos sobre a economia dos países que avançaram sobre o paradigma. Nesse sentido, a análise dos padrões cíclicos de crescimento recai sobre as fases intermediárias (da segunda a quinta fase). Enquanto, na primeira fase, os efeitos econômicos são pequenos e imperceptíveis, nas fases seguintes, à medida que o paradigma se esgota, alcançando a quinta e sexta fase, as oportunidades de investimento se deslocam para os países da periferia, justamente quando o novo paradigma está em gestação ou em implementação nos países centrais ${ }^{7}$. Tal perspectiva

\footnotetext{
${ }^{7}$ Os períodos prolongados de gestação e difusão são óbvios, como o exemplo da tecnologia da informação e da internet. Para Freeman e Soete (1997) e Freeman e Louçã (2001), essas tecnologias tiveram origem nos os avanços da ciência e invenção. Em termos de
} 
implica aumento do gap tecnológico entre os países, e necessidade permanente de adaptação às características estruturais que surgem com as mudanças de padrão originadas nos países avançados.

Surge, nesse sentido, a importância em compreender os fatores que influenciam o processo de difusão das revoluções tecnológicas entre os países, enfatizando o caráter desigual da propagação explicada pela capacidade de mudança social e institucional para permitir o pleno desenvolvimento com o uso de novas tecnologias.

\subsection{Revoluções tecnológicas, mudança institucional e trajetórias de crescimento}

Os sistemas tecnológicos estão presentes de maneira universal nas atividades, de modo a dominar o comportamento de toda a economia durante décadas e, de maneira recíproca, influenciar as maiores mudanças sociais e políticas. No entanto, o amplo processo de mudança estrutural e organizacional no sistema econômico dificilmente se propaga de maneira regular e gradual entre as economias. $\mathrm{O}$ novo paradigma tecnoeconômico não é facilmente aceito de maneira universal, apesar da sua evidente superioridade e lucratividade em muitas aplicações. Isso, porque existem fortes interesses associados ao paradigma precedente, como o regime regulatório e normas culturais, que estão associadas ao antigo paradigma. Dessa forma:

[...] o que muitas vezes tem sido descrito com declínio da onda longa pode ser um período de grande turbulência caracterizada pelo rápido crescimento e alta lucratividade de algumas firmas e indústrias, lado a lado com crescimento lento, tendências declinantes, ou estagnação em outras, assim como conflito político sobre o regime regulatório apropriado. (Freeman; Louçã, 2001, p. 148, tradução nossa).

\footnotetext{
efeitos macroeconômicos, porém, a difusão foi sentida no último quarto do século XX, como afirmam: Elas podem ser ainda maiores nesse início do século XXI, quando a ampla difusão das tecnologias da informação e comunicações afetar todos os países e todos os setores da economia. A taxa de difusão pode diminuir em relação ao período inicial de turbulência, mas o peso dos novos sistemas tecnológicos na economia agregada é agora muito maior, tanto que os efeitos macroeconômicos são enormes. "[...] cada sucessiva revolução industrial mostrou um padrão, embora cada um com suas próprias características" (Freeman; Louçã, 2001, p. 147).
} 
As crises do sistema econômico, turbulências monetárias, altos níveis de desemprego e disputas tarifárias caracterizam fenômenos típicos associados aos períodos de transição de paradigma e de ajuste estrutural. A incompatibilidade da velha estrutura institucional com a nova constelação de tecnologias é resolvida, de maneira variada, nos diferentes países e indústrias. É nesse sentido que cada país apresenta sua própria dinâmica. Como resultado, tem-se observado uma ampla variedade de mudanças institucionais em resposta aos efeitos da difusão das novas tecnologias. Freeman e Louçã (2001) destacam que:

Processos autônomos e semiautônomos de mudança social e institucional nos vários países influenciam o processo de difusão. A propagação do novo paradigma é muito desigual entre as firmas e indústrias, como também entre países. Alguns são afetados de modo profundo e imediato, outros após longo período de defasagem, e outros quase não são afetados. (Freeman; Louçã, 2001, p. 148)

Em uma perspectiva evolucionária, pode-se afirmar que as mudanças de paradigmas não significam que todas as firmas, em todos os países, irão adotar o mesmo modelo organizacional. Mostra apenas que a propagação das tecnologias paradigmáticas (como eletrificação ou a informatização) possui uma ampla influência sobre a economia mundial, ao afetar a evolução do comportamento das firmas; porém, mediante ampla variedade local de adaptação e de experiências históricas locais prévias que influenciam a capacidade de assimilação e assim, as trajetórias de crescimento. Após o período turbulento de mudança estrutural, à medida que o novo paradigma passa a ter aceitação geral, um período de grande estabilidade pode suceder, correspondendo à fase de ascensão ou boom de crescimento da onda longa. No entanto, cada região tem a sua própria dinâmica, mas é dependente das instituições que definem as políticas e estratégias desenvolvimento (Perez; Soete, 1988).

As observações históricas dos processos de desenvolvimento e de emparelhamento tecnológico (catching up) dos países da Europa mostra que esse processo não começou na Revolução Industrial, mas sim na segunda metade do século XIX. Foi na segunda revolução tecnológica que Estados Unidos, Alemanha, França, entre outros países, fizeram o catching up em muitas indústrias e se projetaram na liderança em ou- 
tras. Na terceira e quarta revolução tecnológica ocorreu a propagação para os demais países. Essa histórica irregularidade de propagação entre os países torna a expressão "ondas" longas inapropriada para descrever tal fenômeno, ao dar uma noção de regularidade e uniformidade do processo de difusão. Como destacam Freeman e Louçã (2001, p. 150), a regularidade da difusão das revoluções e paradigmas não corresponde às características dos processos de turbulência econômica historicamente observados. Para os autores:

\begin{abstract}
Algumas indústrias e serviços são profundamente afetados, outros apenas em pequena extensão, mas a velocidade em que essas mudanças ocorrem é consideravelmente variável. Alguns produtos e indústrias serão afetados logo após a primeira emergência e cristalização das novas constelações; outros, apenas décadas mais tarde. (Freeman; Louçã, 2001, p. 150, tradução nossa).
\end{abstract}

A velocidade em que os novos estilos tecnológicos se tornam dominantes, após a sua primeira demonstração de superioridade e potencial amplo de difusão (internacional), é dependente da nova infraestrutura necessária para a sua plena utilização e assimilação. São dois os tipos de infraestruturas necessárias: por um lado, as infraestruturas físicas de comunicação e de transporte; por outro lado, infraestruturas institucionais, que são necessárias para o treinamento e educação nas novas habilidades e para projetar e desenvolver uma nova variedade de produtos e serviços - a infraestrutura científica e tecnológica (Nelson, 2011).

O investimento em ambos os tipos de infraestrutura exige iniciativa política e mudanças no regime regulatório, objeto de intenso debate e conflito político. Isso sugere que os períodos de declínio de crescimento das novas constelações podem ser retardados de várias maneiras pelas velhas estruturas institucionais e sociais, resistentes às mudanças da própria tecnologia. Por outro lado, mudanças políticas, sociais e culturais podem levar ao desenvolvimento de uma estrutura capaz de oferecer suporte para as novas constelações tecnológicas - um novo regime de regulação ${ }^{8}$.

\footnotetext{
${ }^{8}$ Conforme Boyer (1988), as instituições permitem que o processo de acumulação avance de maneira relativamente ordenada durante períodos relativamente longos. Nesse sentido, “[...] cada regime de regulação é designado para controlar e estabilizar uma fase particu-
} 
Portanto, a visão do desenvolvimento na perspectiva evolucionária, proposta por Perez (2010) e Freeman e Louçã (2001), mostra que as mudanças de paradigmas não ocorrem sem profundas mudanças estruturais, isto é, sem a ocorrência de crises de ajustamentos que exigem periódicas mudanças na estrutura institucional e social das economias. O sistema político de um país e sua cultura local também possuem dinâmicas próprias. Nesse sentido, a mudança tecnológica e as mudanças na estrutura da economia não podem ser consideradas sob o ponto de vista do determinismo tecnológico, mas sim como resultado próprio da mudança tecnológica parcialmente determinada pelas influências sociais, políticas e culturais dos países. Existe, portanto, um processo coevolucionário entre instituições, tecnologia e firmas que precisa ser considerado na análise da difusão dos paradigmas e do processo de desenvolvimento dos países.

\section{Propagação tardia das revoluções tecnológicas e as oportunidades do desenvolvimento: considerações finais}

As revoluções tecnológicas representam mudanças estruturais associadas à ascensão de indústrias-chave que permitem sucessivos ganhos de produtividade para todo o sistema. Tal perspectiva tem profundas implicações na compreensão do desenvolvimento econômico em escala global que, longe de apresentar comportamento convergente das trajetórias dos países ao longo do tempo, revela trajetórias diferenciadas entre países e regiões mundiais. A compreensão da forma como tecnologia moderna se propaga e como se dá a repartição dos frutos do progresso tecnológico entre os países resgata preocupações teóricas da escola estruturalista. Nessa perspectiva, Prebisch (1949) destaca que a criação de um núcleo industrial na Grã-Bretanha, de nível técnico

lar de crescimento capitalista", diferindo em relação às características do período anterior (Freeman, 1988, p. 11, tradução nossa). Tal concepção resgata preocupações de Marx com a noção de tensão entre as forças produtivas e as relações de produção. Conforme Freeman e Louçã (2001), enquanto Marx aplica sua teoria para as relações sociais capitalistas em geral, a teoria neoschumpeteriana de Perez (1983) e de Freeman e Perez (1988) sobre paradigmas e ciclos longos é desenvolvida em relação às sucessivas mudanças dentro de uma estrutura de economia predominantemente capitalista (Freeman; Louçã, 2001, p. 151). 
relativamente elevado para a época, deu origem a um processo de irradiação (desigual) da tecnologia moderna em escala mundial:

[...] durante o primeiro século da Revolução Industrial, o núcleo de irradiação se ampliou substancialmente, mas a característica principal da economia contemporânea é a coexistência de um centro, que comanda o desenvolvimento tecnológico, e uma vasta e heterogênea periferia. (Furtado, 1971, p. 134).

O surgimento dos países do centro não forma um núcleo homogêneo; eles formam subconjuntos de importância desigual na economia mundial. No entanto, é o tipo de relação estabelecida entre os países de centro e periferia que é considerada a origem do fenômeno da concentração da renda mundial, que ocorre principalmente por meio da deterioração dos termos de intercâmbio dos países periféricos (Furtado, 1971, p. 135).

Sob o angulo dinâmico de mudança tecnológica e de evolução das estruturas industriais nos países centrais, não existe uma tendência de passagem automática de uma fase para outra. Tal perspectiva revela que a "[...] única tendência visível é que os países subdesenvolvidos continuem a sê-lo" (Furtado, 1971, p. 135). À medida que as tecnologias evoluem e os paradigmas mudam nos países avançados, os países da periferia continuam subdesenvolvidos, atrasados tecnologicamente e dependentes de importação de tecnologia moderna (Perez; Soete, 1988).

Na concepção teórica de Perez (1983) e de Freeman e Louçã (2001), historicamente, cada paradigma se expande em círculos concêntricos de setor para setor, até abarcar toda a estrutura industrial. Em âmbito geográfico, esse processo ocorre dentro de cada país e entre as regiões mundiais. À medida que as condições institucionais vão se tornando favoráveis nos países, todo o tecido econômico tende a adotar o paradigma seguindo suas trajetórias inovadoras gerais, até que sejam "formas normais" de fazer as coisas de maneira eficaz, eficiente e rentável. No entanto, na fase de esgotamento do paradigma e da revolução tecnológica, com a redução do ritmo de crescimento das indústrias, perda de dinamismo tecnológico e saturação dos mercados, induz a um processo de deslocamento das indústrias-núcleo do paradigma para os países atrasados, viabilizando assim, as oportunidades para o processo de industrialização nesses países. Para Perez, 
[...] cada grande onda se desloca para a periferia e apoia o desenvolvimento com as últimas capacidades geradoras de riqueza de suas tecnologias maduras, encontrando a derrota final - ou a transformação - por outro paradigma. (Perez, 2004, p. 110).

A fase final do paradigma, contudo, coincide com as duas primeiras fases da revolução tecnológica seguinte, perpetuando o gap entre os países. Muito embora se destaque a recorrência desse processo na economia mundial, deve-se destacar que não há um determinismo do processo de industrialização dos países periféricos. Apesar dos paradigmas se propagarem tardiamente para os países atrasados, na sua fase final ou de maturidade, é necessária a existência de um ambiente institucional adequado para permitir o desenvolvimento das tecnologias, indústrias e firmas do paradigma. Nesse sentido, Perez e Soete (1988) ressaltam as condições paradoxais que tornam o avanço do desenvolvimento tão difícil para os países. Para os autores:

[...] capital prévio é necessário para produzir novo capital, conhecimento prévio é necessário para absorver novo conhecimento, habilidades devem estar disponíveis para aquisição de novas habilidades e certo nível de desenvolvimento é requerido para criar a infraestrutura e economias de aglomeração que tornam o desenvolvimento possível. Em suma, é dentro dessa lógica dinâmica do sistema que os ricos enriquecem e o gap permanece e se amplia para os mais atrasados. (Perez; Soete, 1988, p. 459, tradução nossa).

O processo de catching up, portanto, não é automático, e as bases para o seu desenvolvimento precisam ser construídas. No entanto, Perez (1983) observa que, em períodos de transição de paradigma, surgem oportunidades que facilitam o avanço do processo de desenvolvimento e do catching up. Para a autora, duas janelas de oportunidade se abrem durante a transição de paradigma: uma na fase inicial das novas tecnologias; e outra, na fase final, quando as tecnologias e indústrias alcançam a fase de maturidade. Porém, as estratégias de desenvolvimento baseadas unicamente nas oportunidades criadas pela propagação tardias das revoluções tecnológicas para a periferia não podem conduzir a uma trajetória efetiva de desenvolvimento e catching up. São novas 
tecnologias que permitem o efetivo avanço e o ingresso em uma trajetória de catching up com os lideres, dado o potencial de inovação, lucratividade e de crescimento, enquanto as tecnologias maduras, esse potencial já está esgotado?.

No entanto, diante das dificuldades e condições paradoxais do desenvolvimento econômico para os países menos desenvolvidos, as tecnologias maduras oferecem a oportunidade para dar início à criação de uma base para o avanço do processo de industrialização, gerando capacidade de aprendizado, infraestrutura e externalidades necessárias para respaldar um esforço maior de desenvolvimento no futuro (Perez, 2001, p. 111).

Por outro lado, as oportunidades de ingressar nas novas indústrias e tecnologias surgem no período inicial das revoluções tecnológicas quando o conhecimento tecnológico não é plenamente dominado pelas firmas e, portanto, quando as barreiras à entrada nos novos sistemas tecnológicos, diante das necessidades de experiências e/ou habilidades de administração e de capital, ainda são menores e incipientes ${ }^{10}$. Contudo, o avanço do desenvolvimento com as novas tecnologias requer elevados níveis de externalidades e existência de conhecimento científico e tecnológico. É a disponibilidade de infraestrutura tecnológica e institucional, com a existência de universidades e de qualificação pessoal que permitiria aos países ingressar de maneira autônoma nas novas indústrias do novo sistema tecnológico em sua fase inicial, viabilizando o êxito da trajetória de desenvolvimento e do processo de catching up. A inexistência

\footnotetext{
${ }^{9}$ Portanto, o ingresso nas fases de maturidade de uma revolução tecnológica não leva à trajetória de desenvolvimento com catching up. Nesse período, as tecnologias maduras apresentam o "[...] mínimo potencial para geração de lucros, enfrentam mercados estagnados e quase não tem espaço para aumentos de produtividade" (Perez, 2001, p. 111). As oportunidades oferecidas na fase de maturidade como ponto de partida para o desenvolvimento é um processo custoso e não é, "nem muito rentável, nem promissor". ${ }^{10}$ Perez e Soete (1988, p. 476) afirmam que grande parte do conhecimento exigido para ingressar em um sistema tecnológico na sua fase inicial é público e disponível nas universidades. Nessa fase, muitas competências e habilidades requeridas ainda estão para ser inventadas na prática. Conforme visto anteriormente, à medida que o sistema evolui o novo conhecimento gerado e as habilidades, que são cumulativas, vão se tornando cada vez mais apropriadas pelas firmas, assumindo uma natureza cada vez mais privada e indisponível para venda entre os competidores. Apenas com o tempo, quando o sistema se aproxima da fase de maturidade que o conhecimento e as habilidades se tornam novamente públicos ou disponíveis para venda no mercado.
} 
desse ambiente em países periféricos e em desenvolvimento dificulta a continuidade do processo endógeno de geração de conhecimento e de formação das habilidades tecnológicas, à medida que o sistema evolui.

O processo de desenvolvimento econômico, portanto, em cada revolução tecnológica, é efetivo apenas se acompanhado de uma variedade de mudanças institucionais designadas, a priori, ao fortalecimento das competências tecnológicas autônomas das firmas nacionais (Freeman, 1995, p. 20). As atividades de aprendizado - sua natureza, determinantes e efeitos econômicos dinâmicos - devem ser o foco da atenção analítica e de políticas futuras para o avanço nas trajetórias de desenvolvimento. O sucesso do desenvolvimento com catching up exige esforços dos países para aproveitar as oportunidades geradas pelos paradigmas. As diferenças institucionais no modo de importar, aperfeiçoar, desenvolver e difundir as novas tecnologias, produtos e processos, definem historicamente as trajetórias de desenvolvimento dos países dentro do contexto histórico da evolução social.

Como observado, desde a revolução industrial até a atual revolução da informação, aqueles países que conseguiram avançar nas trajetórias de crescimento com catching up em cada período histórico foram países que fizeram o ajuste institucional em conformidade com as necessidades das novas tecnologias. Enquanto os países que não avançam na formação das habilidades e no aprendizado tecnológico em conformidade com as novas tecnologias, historicamente, são países que exibem performances de baixo crescimento e seguem trajetórias de falling behind na economia mundial.

\section{Referências}

BOYER, R. Technical Change and theory of 'Régulation'. In: DOSI, G. et al. (Editors). Technical change and economic theory. London: Pinter Publisher, 1988. p. 67-94.

CONCEIÇÃO, C. S. Da Revolução Industrial à Revolução da Informação: uma análise evolucionária da industrialização da América Latina. Tese (Doutorado em Economia), Universidade Federal do Rio Grande do Sul, Faculdade de Ciências Econômicas, Programa de Pós-gradução em Economia, Porto Alegre, 2012.

DOSI, G. Technological paradigms and technological trajectories: a suggested interpretation of the determinants and directions of technical change. Research Policy, $\mathrm{n}$. 11, p. 147-162, 1982. 
DOSI, G. Mudança técnica e transformação industrial: a teoria e uma aplicação à indústria de semicondutores. Campinas: Unicamp, 2006.

DOSI, G. et al. (Ed.). Technical change and economic theory. London: Pinter Publishers, 1988.

DOSI, G.; NELSON, R. R. Technical Change and Industrial Dynamics as Evolutionary Processes. Working paper n. 7, Pisa: LEM, 2009.

FREEMAN, C. Inovação e ciclos longos de desenvolvimento econômico. Porto Alegre: Ensaios FEE, v. 5. p. 5-20, 1984.

. Technology Policy and economic performance: lessons from Japan. London: Pinter Publishers, 1987.

. Technoloy gaps, international trade and the problems of smaller and lessdeveloped economies. In: FREEMAN, C.; LUNDVALL, B. Small countries facing the technologica revolution (Editors). Londres: Pinter Publishers, 1988. p. 67-84.

The National System of Innovation in historical perspective. Cambridge Journal of Economics, v. 19, p. 5-24, 1995.

. Continental, national and sub-national innovation system: complementary and economic growth. Research Policy, v. 31, p. 191-211, 2002.

. Schumpeter's business cycles and techno-economic paradigms. In: DRECHSLER, W.; KATTEL, R., REINERT, E. (Org.). Techno-economic paradigms: essays in honour of Carlota Perez. London: Anthem, 2011. p. 269-286.

. Systems of innovations: selected essays in Evolutionary Economics. Cheltenham: Edward Elgar, 2008.

FREEMAN, C; LOUÇÃ, F. As time goes by: from the Industrial Revolution to the Information Revolution. New York: Oxford University Press, 2001.

FREEMAN, C; PEREZ, C. Structural crisis of adjustment: business cycles and investment behavior. In: DOSI, G. et al. (Editors). Technical change and economic theory. London: Pinter Publisher, 1988. p. 38-66.

FREEMAN, C.; SOETE, L. The economics of industrial innovation. Cambridge: MIT, 1997.

FURTADO, C. Teoria e política do desenvolvimento econômico. São Paulo: Nacional, 1971.

KONDRATIEV, N. D. The long waves in economic life. Review of Economic Statistics, 17, p. 105-115, 1925.

KUHN, T. Estrutura das revoluções cientificas. Lisboa: Perspectiva, 2003.

MARX, K. O capital: crítica da economia política. São Paulo: Editora Difel, 1982.

Grundrisse: manuscritos econômicos de 1857-1858: esboços da crítica da economia política. São Paulo: Boitempo, 2011.

MARX, K.; ENGELS, F. Cartas filosóficas e outros escritos. São Paulo: Editora Grijalbo, 1977. 
NELSON, R. R. Technology, institutions, and economic development. In: DRECHSLER, W.; KATTEL, R., REINERT, E. (Org.). Techno-economic paradigms: essays in honour of Carlota Perez. London: Anthem, 2011. p. 269-286.

PEREZ, C. Structural change and assimilation of new technologies in the economic and social systems. Futures, v. 15, n.5, p. 357-375, out. 1983.

. Microelectronics, long waves, and world structural change: new perspective for developing countries. World development, v. 13, n. 3, p. 441-463, 1985.

. New Technologies and development. In: FREEMAN, C.; LUNDVALL, B. Small countries facing the technologica revolution (Editors). Londres: Pinter, 1988, p. 85-97.

. Technological change and opportunities for development as a moving target. Cepal Review, n. 75, p. 109-130, 2001.

. C. Technological revolution and financial capital: the dynamics of bubbles and golden ages. Cheltenham: Edward Elgar, 2002.

. Revoluciones tecnológicas e capital financeiro: la dinâmica grandes burbujas financieras y las épocas de bonanza. México: Siglo XXI, 2004.

Technological revolutions and techno-economic paradigms. Cambridge Journal of Economics, v. 34, p. 185-202, 2010.

PEREZ, C. SOETE, L. Catching up in technology: entry barriers and windows of opportunity. In: DOSI, G. et al. Technical change and economic theory. London: Pinter Publishers, 1988.

POSSAS, M. L. Concorrência schumpeteriana. In: KUPFER, D.; HASENCLEVER, L. Economia industrial: fundamentos teóricos e práticos no Brasil. Rio de Janeiro: Campus. 2002. p. 415-430.

PREBISCH, R. O desenvolvimento econômico da América Latina e alguns de seus problemas principais. 1949. In: BIELSCHOWSKY, R. Cinquenta anos de pensamento na CEPAL. Rio de Janeiro: Record, 2000. p. 851-886.

ROSENBERG, N. Por dentro da caixa preta: tecnologia e economia. São Paulo: Unicamp, 2006.

SCHUMPETER, J. A. Capitalismo, socialismo e democracia. Rio de Janeiro: Editora Fundo de Cultura, 1961.

. História da análise econômica. Rio de janeiro: Fundo de cultura, 1964.

. Business cycles: a theoretical, historical and statistical analysis of the capitalist process. New York: Porcupine, 1989.

. Teoria do desenvolvimento econômico: uma investigação sobre lucros, capital, credito, juros e ciclo econômico. São Paulo: Nova cultural, 1997. 